\title{
Peri-conception hyperglycaemia and nephropathy are associated with risk of congenital anomaly in women with pre-existing diabetes: a population-based cohort study
}

\author{
R. Bell • S. V. Glinianaia • P. W. G. Tennant • \\ R. W. Bilous $\cdot$ J. Rankin
}

Received: 20 September 2011 / Accepted: 5 December 2011/Published online: 8 February 2012

(C) Springer-Verlag 2012

\begin{abstract}
Aims The aim of this study was to quantify the risk of major congenital anomaly, and to assess the influence of periconception $\mathrm{HbA}_{1 \mathrm{c}}$ and other clinical and socio-demographic factors on the risk of congenital anomaly occurrence in offspring of women with type 1 and type 2 diabetes diagnosed before pregnancy.

Methods This was a population-based cohort study using linked data from registers of congenital anomaly and diabetes in pregnancy. A total of 401,149 singleton pregnancies (1,677 in women with diabetes) between 1996 and 2008 resulting in live birth, fetal death at $\geq 20$ weeks' gestation or termination of pregnancy for fetal anomaly were included. Results The rate of non-chromosomal major congenital anomaly in women with diabetes was 71.6 per 1,000 pregnancies $(95 \%$ CI 59.6, 84.9), a relative risk of 3.8 (95\% CI $3.2,4.5)$ compared with women without diabetes. There was a three- to sixfold increased risk across all common anomaly groups. In a multivariate analysis, peri-conception glycaemic
\end{abstract}

R. Bell $(\bowtie) \cdot S$. V. Glinianaia $\cdot$ P. W. G. Tennant $\cdot$ J. Rankin Institute of Health \& Society, Newcastle University,

Baddiley-Clark Building, Richardson Road,

Newcastle upon Tyne NE2 4AX, UK

e-mail: ruth.bell@ncl.ac.uk

R. Bell · J. Rankin

Regional Maternity Survey Office,

Newcastle upon Tyne, UK

R. W. Bilous

Institute of Cellular Medicine, Newcastle University,

Newcastle upon Tyne, UK

R. W. Bilous

James Cook University Hospital, South Tees NHS Trust,

Middlesbrough, UK control (adjusted OR [aOR] 1.3 [95\% CI 1.2, 1.4] per 1\% [11 $\mathrm{mmol} / \mathrm{mol}]$ linear increase in $\mathrm{HbA}_{1 \mathrm{c}}$ above $6.3 \%$ [45 mmol/mol]) and pre-existing nephropathy (aOR 2.5 [95\% CI 1.1, 5.3]) were significant independent predictors of congenital anomaly. Associations with gestation at booking (aOR 1.1 [95\% CI 1.0, 1.1]) and parity (aOR 1.6 [95\% CI 1.0, 2. 5]) were not significant. Unadjusted risk was higher for women from deprived areas or who did not take folate. Type and duration of diabetes, ethnicity, age, BMI, preconception care, smoking and fetal sex were not associated with congenital anomaly risk.

Conclusions Peri-conception glycaemia is the most important modifiable risk factor for congenital anomaly in women with diabetes. The association with nephropathy merits further study.

Keywords Congenital abnormalities · Diabetes · Hyperglycaemia $\cdot$ Nephropathy $\cdot$ Preconception

\begin{tabular}{|c|c|}
\hline \multicolumn{2}{|c|}{ Abbreviations } \\
\hline $\mathrm{aOR}$ & Adjusted odds ratio \\
\hline EUROCAT & $\begin{array}{l}\text { European surveillance of congenital } \\
\text { anomalies }\end{array}$ \\
\hline ICD & International Classification of Diseases \\
\hline IMD & Index of Multiple Deprivation \\
\hline IQR & Interquartile range \\
\hline LOWESS & Locally weighted scatter plot smoothing \\
\hline NorCAS & Northern Congenital Abnormality Survey \\
\hline NorDIP & Northern Diabetes in Pregnancy Survey \\
\hline
\end{tabular}

Introduction

Pregnancies complicated by pre-existing diabetes are at high risk of adverse outcome, including stillbirth, perinatal 
mortality, congenital anomaly, Caesarean section and macrosomia [1,2]. The global prevalence of type 2 diabetes is increasing particularly at younger ages, resulting in an increasing proportion of pregnancies complicated by diabetes. Congenital anomalies are a major cause of stillbirth and neonatal death for babies born to women with diabetes $[2,3]$ and a substantial proportion end in termination of pregnancy. They are also important contributors to mortality and morbidity throughout infancy and childhood, and survivors may have considerable ongoing health and social care needs.

The risk of congenital anomaly in women with diabetes is strongly associated with glycaemic control, indicated by higher levels of $\mathrm{HbA}_{1 \mathrm{c}}$ in pregnancies affected by congenital anomaly [4-6]. However, similar rates of congenital anomaly have been reported in women with type 1 and 2 diabetes, despite generally lower $\mathrm{HbA}_{1 \mathrm{c}}$ levels in type 2 diabetes [1]. This may reflect differences in other variables that are associated with congenital anomaly risk, such as maternal age, BMI, smoking, ethnicity and socioeconomic status. Previous studies have not assessed the extent to which these factors may modify the effect of glycaemia in the development of congenital anomaly in women with diabetes.

This study combined data from established populationbased registers with comprehensive ascertainment to quantify the risk of major congenital anomaly in pregnancy in women with type 1 and type 2 diabetes, and to assess the influence of clinical and sociodemographic risk factors in addition to peri-conception $\mathrm{HbA}_{1 \mathrm{c}}$.

\section{Methods}

Study population The study area in the north of England (UK) has a population of about 3 million and 31,000 deliveries per year. This analysis included all singleton pregnancies to women resident in the region, resulting in live birth, stillbirth ( $\geq 24$ weeks gestation), late fetal loss (20-23 weeks gestation), or termination of pregnancy following prenatal diagnosis of a fetal anomaly (any gestation), during the period 1996-2008.

Pregnancies in women with and without pre-existing diabetes The Northern Diabetes in Pregnancy Survey (NorDIP) records details of all known pregnancies, irrespective of outcome, in women resident in the study area and diagnosed with diabetes at least 6 months prior to conception [7]. Pregnancies in women with gestational diabetes (i.e. hyperglycaemia first diagnosed during pregnancy) are not included. Demographic and clinical variables are collected, including pre-pregnancy and antenatal $\mathrm{HbA}_{1 \mathrm{c}}$ (DCCT-aligned since 2000). The total number of registered singleton live and stillbirths was obtained from the UK Office for National Statistics.
Congenital anomaly cases The Northern Congenital Abnormality Survey (NorCAS) collects information on all cases of congenital anomaly (up to six anomalies for each case) diagnosed to age 12 years, including those arising in fetal loss or termination of pregnancy for fetal anomaly. The register uses multiple sources of ascertainment [8]. The NorDIP and NorCAS are held on a single linked database at the Regional Maternity Survey Office in Newcastle.

Classification of congenital anomalies All major congenital anomalies were coded according to the International Classification of Diseases 10th revision (ICD-10; www.who.int/ classifications/icd/en/) and categorised using European surveillance of congenital anomalies (EUROCAT) criteria (www.eurocat@ulster.ac.uk), by group (the system affected), subtype (the individual disorder), and syndrome (where applicable). Chromosomal anomalies were defined as any anomaly in the number of chromosomes or in the structure of at least one chromosome resulting in a genetically unbalanced genotype (ICD-10 codes: Q90-92, Q93, Q96-99). Nonchromosomal anomalies are all remaining major congenital anomalies included in the EUROCAT classification scheme $[9,10]$.

Isolated cases (with one anomaly diagnosis only) were assigned to their primary anomaly group and subtype. Cases with two or more non-chromosomal anomalies were reviewed to identify a primary group or subtype, or to confirm a diagnosis of multiple anomalies. Cases were classified as multiple anomalies if they had two or more unrelated anomalies across separate organ systems. Individuals with several anomalies from the same organ system were included within that group but not classified by subtype. A congenital anomaly was classified as isolated if it occurred alone, or if all coexisting anomalies were commonly associated secondary anomalies. Chromosomal anomalies, syndromes (patterns of anomalies arising from a single cause, e.g. genetic disorders [11]), skeletal dysplasias (syndromes of skeletal development [10]), sequences (patterns of anomalies arising from a prior anomaly or mechanical factor [12]), associations (recognised patterns of anomalies of unknown cause [11]) and other microdeletions, were regarded as primary anomalies rather than instances of multiple anomalies.

Statistical analyses Prevalence rates of congenital anomaly, by group and subtype, were determined for women with and without diabetes and compared by calculating the RR, and 95\% CIs for prevalence rates were calculated using exact methods. Numbers of cases are presented only for groups and subtypes where there was at least one case in pregnancies with diabetes. Rates and RRs (95\% CI) for the subtypes of congenital anomalies are presented if there were three or more cases in pregnancies with diabetes. Heterogeneity of RRs between anomaly groups was examined using Cochran's $\mathrm{Q}$ test. 
ORs and associated 95\% CIs for non-chromosomal congenital anomalies among women with diabetes were estimated for various sociodemographic and clinical variables using logistic regression. Independent effects were estimated from an adjusted model, constructed using backwards stepwise regression. All variables with an unadjusted $p$ value below 0.5 were entered into the model (maternal age at delivery, gestational age at booking, peri-conception $\mathrm{HbA}_{1 \mathrm{c}}$, type of diabetes, preconception folic acid, nephropathy diagnosed pre-pregnancy, retinopathy diagnosed pre-pregnancy, fetal sex, parity, pre-pregnancy care, index of multiple deprivation, smoking during pregnancy). Variables were then iteratively removed until all remaining had $p<0.1$. The multivariate analysis had at least adequate power $(\beta=0.8)$ to detect a medium effect (Cohen's $d=0.5$, equivalent to OR of 2.47) for any variable with a baseline exposure probability between $5 \%$ and $95 \%$ (which included type 2 diabetes, non-white ethnicity, preconception folate consumption, pre-pregnancy care, smoking during pregnancy). Greater power was available for the continuous variables (duration of diabetes, maternal age at delivery, maternal BMI at booking, gestational age at booking, and peri-conception $\mathrm{HbA}_{1 \mathrm{c}}$ ).

Interaction terms were used to examine whether variables in the adjusted model had the same effect on the risk of congenital anomalies in women with type 2 compared with type 1 diabetes. The relative contributions of variables in the adjusted model were approximated by estimating the standardised $\beta$ coefficients, which allow the importance of continuous and non-continuous variables to be directly compared [13]. $\mathrm{HbA}_{1 \mathrm{c}}$ was analysed as a single peri-conception variable, using measurement closest to conception (within three months of conception) where available (48.4\% of pregnancies) and mean first trimester value (up to 14 weeks gestation) otherwise. BMI, determined from height and weight at booking, was included as a continuous variable, excluding underweight women due to potential curvilinearity [14]. The index of multiple deprivation (IMD), an area-based measure of socioeconomic status, was determined from maternal residential postcode at booking and grouped into tertiles [15]. Locally weighted scatter plot smoothing (LOWESS), with smoothing parameter 0.8 , was used to investigate the shape of the relationship between $\mathrm{HbA}_{1 \mathrm{c}}$, as a continuous variable, and the risk of congenital anomaly. CIs for the LOWESS plot were estimated by bootstrapping (50,000 iterations).

Statistical analyses were performed using SPSS for Windows version 17.0 (IBM Corporation, Somers, NY, USA) and Stata 11.1 (StataCorp, College Station, TX, USA). $P<$ 0.05 was considered statistically significant.

Ethics approval and research governance NorCAS, as part of the British Isles Network of Congenital Anomaly Registers, has exemption from the UK National Information and Governance Board (PIAG 2-08(e)/2002 20/06/2002) from a requirement for individual consent and has ethics approval (09/H0405/48) to undertake studies using the data. Newcastle Research Ethics Committee originally granted approval for the NorDIP in 1993, and data are now obtained and held with informed consent.

\section{Results}

Study population Overall, 401,149 singleton live births, stillbirths, late fetal losses, and terminations of pregnancy were recorded during the study period, including 1,677 in women with pre-existing diabetes, giving a prevalence of 4.2 per $1,000(95 \%$ CI $4.0,4.4)$ pregnancies.

Among women with diabetes, median (interquartile range, IQR) maternal age at delivery was 30 (25-24) years; $649(40.1 \%)$ women were primiparous and the median (IQR) peri-conception $\mathrm{HbA}_{1 \mathrm{c}}$ was $7.9 \%$ (6.8-9.2). A total of 1314 (78.4\%) women had type 1 and 363 (21.6\%) had type 2 diabetes. There were significant differences in the characteristics of women with type 1 and type 2 diabetes (Tables 1 and 2). Overall reported preconception folate consumption was low, but not significantly different in women with type 1 and type 2 diabetes $(p=0.06)$.

Risk of congenital anomaly A total of 9,488 singleton pregnancies were affected by at least one major congenital anomaly, including 129 in women with diabetes. The risk of a pregnancy affected by any major congenital anomaly in women with diabetes was over three times higher than the background population (RR 3.3 [95\% CI 2.8, 3.9]; Table 3). There was no difference in the proportion of affected pregnancies ending in termination for fetal anomaly in women with and without diabetes: 23 (18\%) vs 1,811 (19\%); RR 0.9 (95\% CI 0.6, 1.3).

The prevalence of major congenital anomaly per 1,000 pregnancies was $82.2(95 \%$ CI $67.9,98.3)$ in women with type 1 diabetes and $57.9(95 \%$ CI $36.2,87.1)$ in women with type 2 . There was no significant difference in risk of congenital anomaly by type of diabetes (RR 1.4 [95\% CI $0.9,2.2]$ for type 1 vs type 2).

There was no evidence of increased risk of chromosomal anomalies in women with diabetes (RR 1.2 [95\% CI 0.6, 2.4]). Excluding chromosomal anomalies, the relative risk of affected pregnancy for women with diabetes was 3.8 $(95 \%$ CI 3.2, 4.5). There was significant variation in relative risk between different groups of non-chromosomal anomaly ( $p=0.05$ ), attributable to a 12-fold increase for the sequence group (including caudal dysplasia sequence, sirenomelia and partial urorectal septum malformation sequence) among women with diabetes (Table 3).

Among pregnancies in women without diabetes, the rate of non-chromosomal anomaly was significantly higher in 
Table 1 Characteristics of mothers with type 1 and type 2 diabetes (continuous variables) ${ }^{\text {a }}$

\begin{tabular}{|c|c|c|c|c|c|c|c|}
\hline \multirow[t]{2}{*}{ Continuous variable } & \multicolumn{3}{|c|}{ Type $1(n=1314)$} & \multicolumn{3}{|c|}{ Type $2(n=363)$} & \multirow[t]{2}{*}{$p$ value } \\
\hline & $n$ & Range & Median (IQR) & $n$ & Range & Median (IQR) & \\
\hline Duration of diabetes (years) & 1,303 & $0.9-36$ & $2(6-18)$ & 352 & $1-19$ & $2(1-4)$ & $<0.001$ \\
\hline Maternal age at delivery (years) & 1,314 & $15-46$ & $29(24-33)$ & 363 & $17-46$ & $33(29-37)$ & $<0.001$ \\
\hline BMI at booking $\left(\mathrm{kg} / \mathrm{m}^{2}\right)$ & 1,010 & $17-52$ & $25.5(23-29)$ & 283 & $19-64$ & $34.6(29-40)$ & $<0.001$ \\
\hline Gestational age at booking (weeks) & 1,308 & $1-34$ & $8(7-11)$ & 358 & $2-34$ & $9(7-12)$ & 0.009 \\
\hline Peri-conception $\mathrm{HbA}_{1 \mathrm{c}}(\%)$ & 1,146 & $5-16.4$ & $8.1(7.0-9.3)$ & 291 & $4.6-15.3$ & $7.0(6.2-8.2)$ & $<0.001$ \\
\hline Peri-conception $\mathrm{HbA}_{1 \mathrm{c}}(\mathrm{mmol} / \mathrm{mol})$ & 1,146 & $31.1-155.7$ & $65.0(53.0-78.1)$ & 291 & $26.8-143.7$ & $53.0(44.3-66.1)$ & $<0.001$ \\
\hline
\end{tabular}

${ }^{\mathrm{a}}$ Includes chromosomal and non-chromosomal anomalies

males (RR 1.2 [95\% CI 1.1, 1.2]). This sex difference was not apparent among pregnancies in women with diabetes (RR 0.9 [95\% CI 0.6, 1.2] for males vs females), although the risk ratio did not differ significantly from that observed in the general population.

Predictors of non-chromosomal congenital anomalies in women with diabetes Peri-conception $\mathrm{HbA}_{1 \mathrm{c}}$ and presence of pre-pregnancy nephropathy were significant independent predictors of congenital anomaly (Table 4). For each percentage $(11 \mathrm{mmol} / \mathrm{mol})$ increase in $\mathrm{HbA}_{1 \mathrm{c}}$, the odds of a pregnancy being affected by congenital anomaly increased by $30 \%$ (adjusted odds ratio (aOR) 1.3 [95\% CI 1.2, 1.4]). LOWESS indicated that this was a steadily increasing effect for $\mathrm{HbA}_{1 \mathrm{c}}$ values above $6.3 \%(45 \mathrm{mmol} / \mathrm{mol})$ (Fig. 1 and Table 5). There was no evidence of risk reduction below this value, although there were very few cases in this range.

Pre-pregnancy nephropathy was associated with greater than two-fold increased risk of congenital anomaly (aOR 2.5 [95\% CI 1.1, 5.3]). Gestation at booking in weeks (aOR 1.1 [95\% CI 1.0, 1.1]) and parity (aOR 1.6 [95\% CI 1.0, 2.5]) were also included in the final adjusted logistic regression model $(p<0.1)$ although the associations did not quite reach the nominated significance level $(p<0.05)$. Of the four variables that were retained in the adjusted model, the highest predictive contribution was attributable to $\mathrm{HbA}_{1 \mathrm{c}}$ (standardised beta coefficient, $\beta=0.41$ ), which was more than twice as important as parity $(\beta=0.19)$, and over 2.5 times more important than gestational age at booking $(\beta=0.16)$ and nephropathy $(\beta=0.15)$.

In univariate analysis, socioeconomic status (OR 2.0 [95\% CI 1.2, 3.2]) and lack of folic acid (OR 2.0 [95\% CI $1.3,3.3]$ ) were significant predictors of pregnancy affected by congenital anomaly. However, these effects were attenuated below significance when adjustment was made for $\mathrm{HbA}_{1 \mathrm{c}}$. There was no evidence that any of the associations between variables in the adjusted model and the risk of congenital anomalies was different in women with type 2 diabetes compared with women with type 1 diabetes.
Type and duration of diabetes, fetal sex, maternal ethnicity, early pregnancy BMI, smoking during pregnancy, prepregnancy retinopathy, and neuropathy were not significantly associated with the risk of congenital anomaly in either unadjusted or adjusted models.

\section{Discussion}

This population-based cohort study provides robust estimates of the risk of major congenital anomaly among offspring of women with pre-existing diabetes. Overall, one in 13 singleton deliveries $(7.7 \%)$ was affected, and the rate of non-chromosomal anomaly was almost four times higher than in women without pre-existing diabetes. Peri-conception $\mathrm{HbA}_{1 \mathrm{c}}$ has previously been reported to be associated with congenital anomaly [4], but the association with pre-existing nephropathy is, to our knowledge, previously unreported. The risk of congenital anomaly increased linearly with increasing $\mathrm{HbA}_{1 \mathrm{c}}$ above $6.3 \%$ (45 mmol/mol), by nearly $30 \%$ for each $1 \%(11 \mathrm{mmol} / \mathrm{mol})$ increase.

This study linked independently and robustly ascertained congenital anomaly cases with detailed clinical information on pregnancies in women with diabetes, notified to longstanding population-based registers. This minimised potential detection bias between pregnancies in women with and without diabetes, and enabled exploration of the independent effects of a wide range of clinical and sociodemographic risk factors. Ascertainment and coding of anomalies was consistent throughout, standardised according to internationally agreed criteria, and independent of diabetes status. We restricted our analysis to EUROCAT defined major anomalies, because these are consistently ascertained, and have the greatest impact on mortality and morbidity. Pregnancies in women with diabetes are subject to increased antenatal surveillance, leading to the potential for ascertainment bias unless, as in NorCAS, cases are notified whenever diagnosed in childhood (to age 12 years). This is particularly important for cardiovascular anomalies, many of which are only diagnosed in early 
Table 2 Characteristics of mothers with type 1 and type 2 diabetes (categorical variables) ${ }^{\mathrm{a}}$
${ }^{a}$ Includes chromosomal and non-chromosomal anomalies

\begin{tabular}{|c|c|c|c|c|c|}
\hline \multirow[t]{2}{*}{ Categorical variable } & \multicolumn{2}{|c|}{ Type $1(n=1314)$} & \multicolumn{2}{|c|}{ Type $2(n=363)$} & \multirow[t]{2}{*}{$p$ value } \\
\hline & $n$ & $\%$ & $n$ & $\%$ & \\
\hline Complicated by a congenital anomaly & 108 & 8.2 & 21 & 5.8 & 0.12 \\
\hline \multicolumn{6}{|l|}{ Preconception folic acid } \\
\hline Yes & 424 & 32.3 & 98 & 27.0 & \multirow[t]{3}{*}{0.06} \\
\hline No & 810 & 61.6 & 223 & 61.4 & \\
\hline Missing & 80 & 6.1 & 42 & 11.6 & \\
\hline \multicolumn{6}{|l|}{ Nephropathy (pre-pregnancy) } \\
\hline Yes & 57 & 4.3 & 3 & 0.8 & \multirow[t]{2}{*}{0.002} \\
\hline No & 1,257 & 95.7 & 360 & 99.2 & \\
\hline \multicolumn{6}{|l|}{ Neuropathy (pre-pregnancy) } \\
\hline Yes & 28 & 2.1 & 0 & 0.0 & \multirow[t]{2}{*}{0.01} \\
\hline No & 1,286 & 97.9 & 363 & 100.0 & \\
\hline \multicolumn{6}{|l|}{ Retinopathy (pre-pregnancy) } \\
\hline Yes & 263 & 20.0 & 16 & 4.4 & \multirow[t]{3}{*}{$<0.001$} \\
\hline No & 992 & 75.5 & 323 & 89.0 & \\
\hline Missing & 59 & 4.5 & 24 & 6.6 & \\
\hline \multicolumn{6}{|l|}{ Pre-pregnancy care } \\
\hline Yes & 583 & 44.4 & 106 & 29.2 & \multirow[t]{2}{*}{$<0.001$} \\
\hline No & 731 & 55.6 & 257 & 70.8 & \\
\hline \multicolumn{6}{|l|}{ Fetal sex } \\
\hline Male & 707 & 53.8 & 179 & 49.3 & \multirow[t]{3}{*}{0.13} \\
\hline Female & 601 & 45.7 & 182 & 50.1 & \\
\hline Uncertain/missing & 6 & 0.5 & 2 & 0.6 & \\
\hline \multicolumn{6}{|l|}{ Smoking during pregnancy } \\
\hline Yes & 290 & 22.1 & 81 & 22.3 & \multirow[t]{3}{*}{0.92} \\
\hline No & 910 & 69.2 & 246 & 67.8 & \\
\hline Missing & 114 & 8.7 & 36 & 9.9 & \\
\hline \multicolumn{6}{|l|}{ Parity } \\
\hline Primipara $($ parity $=0)$ & 559 & 42.5 & 90 & 24.8 & \multirow[t]{3}{*}{$<0.001$} \\
\hline Parity $\geq 1$ & 710 & 54.0 & 243 & 66.9 & \\
\hline Missing & 45 & 3.4 & 30 & 8.3 & \\
\hline \multicolumn{6}{|l|}{ Ethnicity } \\
\hline White & 1,278 & 97.3 & 286 & 78.8 & \multirow[t]{3}{*}{$<0.001$} \\
\hline Other & 31 & 2.4 & 70 & 19.3 & \\
\hline Missing & 5 & 0.4 & 7 & 1.9 & \\
\hline \multicolumn{6}{|l|}{ IMD } \\
\hline Tertile 1 (most deprived) & 385 & 29.3 & 171 & 47.1 & \multirow[t]{4}{*}{$<0.001$} \\
\hline Tertile 2 & 442 & 33.6 & 115 & 31.7 & \\
\hline Tertile 3 (least deprived) & 481 & 36.6 & 76 & 20.9 & \\
\hline Missing & 6 & 0.5 & 1 & 0.3 & \\
\hline
\end{tabular}

childhood. Most previous cohort studies of anomalies in pregnancies complicated by diabetes include only those diagnosed antenatally or apparent shortly after birth, a major methodological limitation [2, 3, 5, 16-19].

This is one of the largest cohort studies to date, including 120 cases of major non-chromosomal anomaly in women with both type 1 and type 2 diabetes, and the only such study to include detailed clinical information. The north of England benefits from a long history of collaborative clinical networking within maternity and neonatal services, and the NorCAS and NorDIP surveys were initiated by pioneering clinicians in the 1980s and 1990s. The surveys are now supported by the Regional Maternity Survey Office (RMSO) which provides a focus for data collection and dissemination 
Table 3 Rates (95\% CI) of major groups and selected subtypes of congenital anomalies ${ }^{\mathrm{a}}$ in pregnancies of women with and without pre-existing diabetes per 1000 singleton pregnancies and RR (95\% CI\%)

\begin{tabular}{|c|c|c|c|c|c|}
\hline \multirow[t]{2}{*}{ Group (subtype) ${ }^{\mathrm{a}}$} & \multicolumn{2}{|c|}{ Pregnancies with diabetes } & \multicolumn{2}{|c|}{ Pregnancies without diabetes } & \multirow[t]{2}{*}{ Relative $\operatorname{risk}(95 \% \mathrm{CI})$} \\
\hline & $n$ & Rate $(95 \% \mathrm{CI})$ & $n$ & Rate $(95 \% \mathrm{CI})$ & \\
\hline Nervous system & 16 & $9.5(5.4,15.4)$ & 769 & $1.9(1.8,2.1)$ & $5.0(3.0,8.1)$ \\
\hline Neural tube defects & 10 & $6.0(2.9,10.9)$ & 443 & $1.1(1.0,1.2)$ & $5.4(2.9,10.1)$ \\
\hline Hydrocephalus & & 2 & & 115 & \\
\hline Microcephaly & & 1 & & 55 & \\
\hline Holoprosencephaly & & 1 & & 31 & \\
\hline Eye & 2 & & 98 & & \\
\hline Cardiovascular system & 44 & $26.2(19.1,35.1)$ & 2919 & $7.3(7.0,7.6)$ & $3.6(2.7,4.8)$ \\
\hline Transposition of great vessels & 3 & $1.8(0.4,5.2)$ & 130 & $0.3(0.3,0.4)$ & $5.5(1.8,17.2)$ \\
\hline Single ventricle & 1 & & 13 & & \\
\hline Ventricular septal defect & 21 & $12.5(7.8,19.1)$ & 1285 & $3.2(3.0,3.4)$ & $3.9(2.6,6.0)$ \\
\hline Atrial septal defect & 1 & & 217 & & \\
\hline Atrioventricular septal defect & 2 & & 69 & & \\
\hline Tetralogy of Fallot & 4 & $2.4(0.76 .0)$ & 95 & $0.24(0.2,0.3)$ & $10.0(3.7,27.2)$ \\
\hline Pulmonary valve stenosis & 3 & $1.8(0.4,5.2)$ & 244 & $0.6(0.5,0.7)$ & $2.9(0.9,9.1)$ \\
\hline Hypoplastic left heart & 1 & & 78 & & \\
\hline Coarctation of aorta & 2 & & 101 & & \\
\hline Total anomalous pulmonary venous return & 1 & & 35 & & \\
\hline Orofacial clefts & 1 & & 437 & & \\
\hline Digestive system & 10 & $6.0(2.9,10.9)$ & 421 & $1.05(0.95,1.15)$ & $5.7(3.0,10.6)$ \\
\hline Oesophageal atresia & 2 & & 43 & & \\
\hline Duodenal atresia or stenosis & 1 & & 36 & & \\
\hline Hirschprung's disease & 1 & & 51 & & \\
\hline Atresia of bile ducts & 1 & & 15 & & \\
\hline Diaphragmatic hernia & 2 & & 91 & & \\
\hline Urinary & 12 & $7.2(3.7,12.5)$ & 974 & $2.4(2.3,2.6)$ & $2.9(1.7,5.2)$ \\
\hline Cystic kidney disease & 2 & & 200 & & \\
\hline Congenital hydronephrosis & 1 & & 20 & & \\
\hline Bladder exstrophy & 1 & & 14 & & \\
\hline Genital & 2 & & 76 & & \\
\hline Limb & 2 & & 234 & & \\
\hline Musculoskeletal & 3 & $1.8(0.4,5.2)$ & 55 & $0.14(0.1,0.2)$ & $13.0(4.1,41.5)$ \\
\hline Syndrome (monogenic or unknown) & 11 & $6.6(3.2,11.7)$ & 439 & $1.1(1.0,1.2)$ & $6.0(3.1,10.9)$ \\
\hline $\begin{array}{l}\text { Laterality syndrome } \\
\text { (right/left atrial isomerism, situs inversus) }\end{array}$ & 6 & $3.6(1.3,7.8)$ & 25 & $0.06(0.04,0.09)$ & $57.2(23.5,139.2)$ \\
\hline Angelman syndrome & 1 & & 6 & & \\
\hline Blepharophimosis-ptosis syndrome & 1 & & 3 & & \\
\hline Laurence-Moon syndrome & 1 & & 2 & & \\
\hline Prader-Willi syndrome & 1 & & 10 & & \\
\hline Incontinentia pigmenti & 1 & & 6 & & \\
\hline Associations & 1 & & 34 & & \\
\hline Sequence & 7 & $4.2(1.6,8.6)$ & 139 & $0.35(0.3,0.4)$ & $12.0(5.6,25.6)$ \\
\hline Caudal dysplasia sequence & 5 & $3.0(0.9,6.9)$ & 7 & $0.02(0.01,0.03)$ & $170.2(54.1,535.6)$ \\
\hline Sirenomelia & 1 & & 6 & & \\
\hline Partial urorectal septum malformation sequence & 1 & & 21 & & \\
\hline Multiple anomalies & 9 & $5.4(2.5,10.2)$ & 440 & $1.1(1.0,1.2)$ & $4.9(2.5,9.4)$ \\
\hline Total non-chromosomal & 120 & $71.6(59.6,84.9)$ & 7613 & $19.1(18.6,19.5)$ & $3.8(3.2,4.5)$ \\
\hline Chromosomal anomalies & 9 & $5.4(2.5,10.2)$ & 1747 & $4.4(4.2,4.6)$ & $1.2(0.6,2.4)$ \\
\hline Grand total & 129 & $76.9(64.6,90.8)$ & 9359 & $23.4(23.0,23.9)$ & $3.3(2.8,3.9)$ \\
\hline
\end{tabular}

${ }^{a}$ EUROCAT coding 
Table 4 Association of maternal and fetal factors with non-chromosomal congenital anomalies in offspring of women with pre-existing diabetes (results of univariate and multivariate logistic regression)
${ }^{a}$ Adjusted model was constructed using backwards stepwise regression. All variables with an unadjusted $p$ value below 0.5 were entered into the model (maternal age at delivery, gestational age at booking, peri-conception $\mathrm{HbA}_{1 \mathrm{c}}$, type of diabetes, preconception folic acid, nephropathy diagnosed pre-pregnancy, retinopathy diagnosed pre-pregnancy, fetal sex, parity, pre-pregnancy care, IMD, smoking during pregnancy). Variables were then iteratively removed until all remaining had $p<0.1$, details of which are shown ${ }^{\mathrm{b}}$ Continuous variable

\begin{tabular}{|c|c|c|c|c|}
\hline \multirow[t]{2}{*}{ Category } & \multicolumn{4}{|l|}{ Number $(\%)$} \\
\hline & $\begin{array}{l}\text { Total } \\
\text { pregnancies } \\
(n=1668)\end{array}$ & $\begin{array}{l}\text { With congenital } \\
\text { anomalies } \\
(n=120)\end{array}$ & $\begin{array}{l}\text { Unadjusted } \\
\text { OR }(95 \% \mathrm{CI})\end{array}$ & $\begin{array}{l}\text { Adjusted OR } \mathrm{OR}^{\mathrm{a}} \\
(95 \% \mathrm{CI})\end{array}$ \\
\hline Duration of diabetes (years) ${ }^{b}$ & 1,646 & 117 & $1.00(0.97,1.02$ & \\
\hline $\begin{array}{l}\text { Maternal age at } \\
\text { delivery (years) }\end{array}$ & 1,668 & 120 & $0.98(0.95,1.01)$ & \\
\hline BMI at booking $\left(\mathrm{kg} / \mathrm{m}^{2}\right)^{\mathrm{b}}$ & 1,277 & 95 & $1.00(0.97,1.03)$ & \\
\hline Gestation at booking (weeks) ${ }^{\mathrm{b}}$ & 1,657 & 120 & $1.04(1.00,1.08)$ & $1.05(1.00,1.11)$ \\
\hline Peri-conception $\mathrm{HbA}_{1 \mathrm{c}}(\%)^{\mathrm{b}}$ & 1,428 & 96 & $1.30(1.18,1.43)$ & $1.30(1.18,1.43)$ \\
\hline \multicolumn{5}{|l|}{ Type of diabetes } \\
\hline Type 1 & 1,306 & $100(7.7)$ & $1.42(0.86,2.33)$ & \\
\hline Type 2 & 362 & $20(5.5)$ & 1.00 & \\
\hline \multicolumn{5}{|l|}{$\begin{array}{l}\text { Preconception folate } \\
\text { supplement }\end{array}$} \\
\hline Taken & 518 & $22(4.2)$ & 1.00 & \\
\hline Not taken & 1,028 & $85(8.3)$ & $2.03(1.26,3.29)$ & \\
\hline \multicolumn{5}{|l|}{$\begin{array}{l}\text { Nephropathy diagnosed } \\
\text { pre-preg }\end{array}$} \\
\hline No & 1,609 & $110(6.8)$ & 1.00 & 1.00 \\
\hline Yes & 59 & $10(16.9)$ & $2.78(1.37,5.64)$ & $2.45(1.14,5.25)$ \\
\hline \multicolumn{5}{|l|}{$\begin{array}{l}\text { Neuropathy diagnosed } \\
\text { pre-preg }\end{array}$} \\
\hline No & 1,640 & $118(7.2)$ & 1.00 & \\
\hline Yes & 28 & $2(7.1)$ & $0.99(0.23,4.23)$ & \\
\hline \multicolumn{5}{|l|}{$\begin{array}{l}\text { Retinopathy diagnosed } \\
\text { pre-preg }\end{array}$} \\
\hline No & 1,308 & $85(6.5)$ & 1.00 & \\
\hline Yes & 277 & $24(8.7)$ & $1.37(0.85,2.19)$ & \\
\hline \multicolumn{5}{|l|}{ Fetal sex } \\
\hline Female & 779 & $59(7.6)$ & 1.00 & \\
\hline Male & 881 & $57(6.5)$ & $0.84(0.58,1.23)$ & \\
\hline \multicolumn{5}{|l|}{ Parity } \\
\hline Primipara $(0)$ & 648 & $43(6.6)$ & 1.00 & 1.00 \\
\hline Multipara $(\geq 1)$ & 945 & $76(8.0)$ & $1.23(0.84,1.81)$ & $1.56(1.00,2.45)$ \\
\hline \multicolumn{5}{|l|}{ Pre-pregnancy care } \\
\hline Yes & 683 & $41(6.0)$ & 1.00 & \\
\hline No & 985 & $79(8.0)$ & $1.37(0.92,2.02)$ & \\
\hline \multicolumn{5}{|l|}{ IMD (tertiles) } \\
\hline 1 (most deprived) & 551 & $52(9.4)$ & $1.96(1.22,3.16)$ & \\
\hline 2 (middle) & 555 & $40(7.2)$ & $1.46(0.89,2.41)$ & \\
\hline 3 (least deprived) & 555 & $28(5.0)$ & 1.00 & \\
\hline \multicolumn{5}{|l|}{ Smoking during pregnancy } \\
\hline No & 11,48 & $80(7.0)$ & 1.00 & \\
\hline Yes & 370 & $31(8.4)$ & $1.22(0.79,1.88)$ & \\
\hline \multicolumn{5}{|l|}{ Ethnicity } \\
\hline White & 1,555 & $112(7.2)$ & 1.00 & \\
\hline Other & 101 & $8(7.9)$ & $1.11(0.53,2.34)$ & \\
\hline \multicolumn{5}{|l|}{$\mathrm{HbA}_{1 \mathrm{c}}$ measurement recorded } \\
\hline Pre-pregnancy & 807 & $52(6.4)$ & 1.00 & \\
\hline 1st trimester & 621 & $44(7.1)$ & $1.11(0.73,1.68)$ & \\
\hline
\end{tabular}


Fig. 1 Association between peri-conception $\mathrm{HbA}_{1 \mathrm{c}}$ in women with pre-existing diabetes and the risk (with $95 \%$ CIs) of a pregnancy affected by major congenital anomaly. To convert values for $\mathrm{HbA}_{1 \mathrm{c}}$ in $\%$ into $\mathrm{mmol} / \mathrm{mol}$, subtract 2.15 and multiply by 10.929

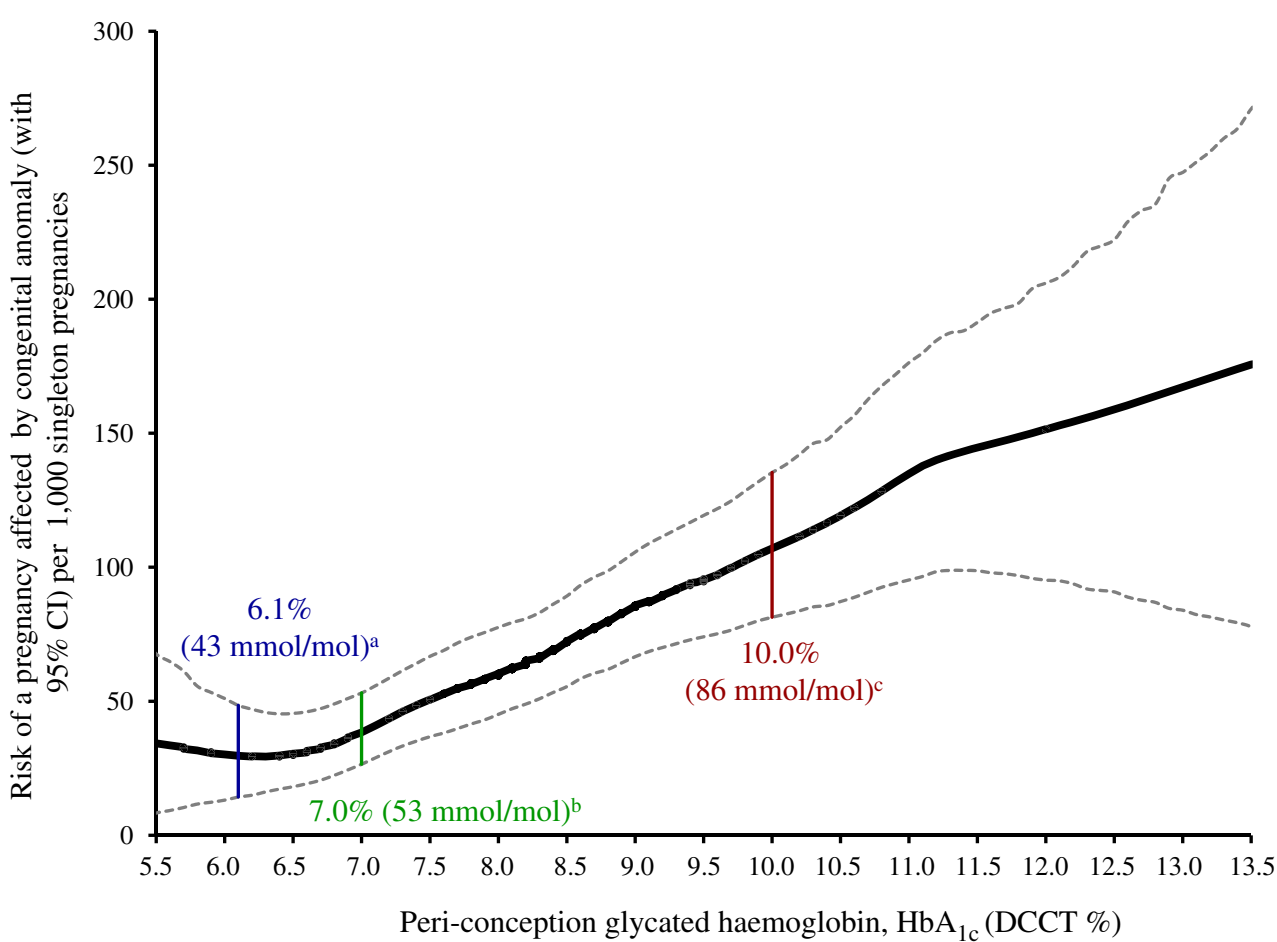

\begin{tabular}{r|c|c|c|c|c|c|c|c|}
\cline { 2 - 9 } $\mathrm{HbA}_{1 \mathrm{c}}$ & $5.5-6.4$ & $6.5-7.4$ & $7.5-8.4$ & $8.5-9.4$ & $9.5-10.4$ & $10.5-11.4$ & $11.5-12.4$ & $12.5-13.5$ \\
Singleton & 195 & 322 & 346 & 220 & 158 & 70 & 32 & 24 \\
pregnancies & 6 & 10 & 21 & 19 & 17 & 10 & 4 & 5 \\
Cases & 6 & & &
\end{tabular}

${ }^{a}$ National Institute for Health and Clinical Excellence (UK), 2008: (1.1.4.2) 'If it is safely achievable, women with diabetes who are planning to become pregnant should aim to maintain their $\mathrm{HbA}_{1 \mathrm{c}}$ below $6.1 \%$. Women should be reassured that any reduction in $\mathrm{HbA}_{1 \mathrm{c}}$ towards the target of $6.1 \%$ is likely to reduce the risk of congenital malformations.' [27]

${ }^{b}$ American Diabetes Association (USA), 2011: (VII.B) ' $\mathrm{A}_{1 \mathrm{c}}$ levels should be as close to normal as possible $(<7 \%)$ in an individual patient before conception is attempted.' [26]

'National Institute for Health and Clinical Excellence (UK), 2008: (1.1.4.3) 'Women with diabetes whose $\mathrm{HbA}_{1 \mathrm{c}}$ is above $10 \%$ should be strongly advised to avoid pregnancy.' [27] across a number of linked surveys of maternal and perinatal health outcome (www.rmso.org.uk).

$\mathrm{HbA}_{1 \mathrm{c}}$ was measured within three months prior to conception in nearly half of cases, and this is likely to reflect periconception glycaemia better than first trimester measurements. However, information on covariates such as maternal age and parity was not available for unaffected pregnancies in women without diabetes, and we were therefore unable to adjust our relative risk estimates. Few of the women with diabetes were of non-white ethnicity. Robust information about hypoglycaemic therapy was not available, so we were unable to investigate any potential association with congenital anomaly risk. The study may have lacked power to quantify the relative risk for anomalies with a small effect size, or where very few cases were reported. In the multivariate analyses, we estimated that we had adequate power to detect a medium effect size for almost all variables examined. The study may have missed some associations with smaller effect sizes.
We estimated the relative risk of non-chromosomal congenital anomaly in the offspring of women with existing diabetes to be nearly four-fold higher than the general population. Previously published estimates range from two- to threefold $[2,3,16,17,20]$ to tenfold $[21,22]$. Direct comparison with the current study is difficult due to differences in ascertainment and classification of anomalies, and lack of comparable risk estimates for offspring of women without diabetes. In a large cohort of births to women with diabetes from England, Wales and Northern Ireland (CEMACH enquiry), the prevalence of major non-chromosomal anomaly was $4.6 \%$, compared with $7.2 \%$ in the current study. This difference may reflect the fact that $\mathrm{CEMACH}$ did not have access to a population-based register and only identified cases apparent within 28 days of delivery. Our study is populationbased and draws on multiple sources to identify cases of anomaly diagnosed at any time up to age 12 years. Underascertainment is also likely to explain the CEMACH study's low reported prevalence ratio of 2.2 for congenital anomaly in 
Table 5 Risk of a pregnancy affected by major congenital anomaly in women with pre-existing diabetes, by peri-conception $\mathrm{HbA}_{1 \mathrm{c}}$
${ }^{\mathrm{a}, \mathrm{b}, \mathrm{c}}$ For further explanation see Fig. 1

IFCC, International Federation of Clinical Chemistry and Laboratory Medicine

\begin{tabular}{|c|c|c|c|}
\hline \multicolumn{2}{|c|}{$\begin{array}{l}\text { Peri-conception glycated } \\
\text { haemoglobin }\left(\mathrm{HbA}_{1 \mathrm{c}}\right)\end{array}$} & \multicolumn{2}{|c|}{ Risk of a pregnancy affected by congenital anomaly $(95 \% \mathrm{CI})$} \\
\hline DCCT $(\%)$ & IFCC $(\mathrm{mmol} / \mathrm{mol})$ & Per 1,000 singleton pregnancies & For individual singleton pregnancy \\
\hline 5.5 & 37 & $34.3(8.3,67.6)$ & 1 in $29(15,121)$ \\
\hline 6.0 & 42 & $30.2(13.1,51.0)$ & 1 in $33(20,76)$ \\
\hline $6.1^{\mathrm{a}}$ & $43^{\mathrm{a}}$ & $29.7(14.3,48.5)$ & 1 in $34(21,70)$ \\
\hline 6.5 & 48 & $30.3(18.1,45.5)$ & 1 in $33(22,55)$ \\
\hline $7.0^{\mathrm{b}}$ & $53^{\mathrm{b}}$ & $38.4(26.5,53.1)$ & 1 in $26(19,38)$ \\
\hline 7.5 & 58 & $50.6(36.8,66.8)$ & 1 in $20(15,27)$ \\
\hline 8.0 & 64 & $60.1(45.1,77.6)$ & 1 in $17(13,22)$ \\
\hline 8.5 & 69 & $72.3(55.5,89.3)$ & 1 in $14(11,18)$ \\
\hline 9.0 & 75 & $85.5(66.7,105.7)$ & 1 in $12(9,15)$ \\
\hline 9.5 & 80 & $95.3(74.1,119.4)$ & 1 in $10(8,13)$ \\
\hline $10.0^{\mathrm{c}}$ & $86^{\mathrm{c}}$ & $107.1(81.4,135.4)$ & 1 in $9(7,12)$ \\
\hline 10.5 & 91 & $119.3(87.2,152.3)$ & 1 in $8(7,11)$ \\
\hline 11.0 & 97 & $134.9(95.3,176.4)$ & 1 in $7(6,10)$ \\
\hline 11.5 & 102 & $144.7(98.7,191.4)$ & 1 in $7(5,10)$ \\
\hline 12.0 & 108 & $151.5(95.2,206.1)$ & 1 in $7(5,11)$ \\
\hline 12.5 & 113 & $158.9(90.8,222.2)$ & 1 in $6(5,11)$ \\
\hline 13.0 & 119 & $167.2(84.0,247.4)$ & 1 in $6(4,12)$ \\
\hline 13.5 & 124 & $175.7(77.8,271.0)$ & 1 in $6(4,13)$ \\
\hline
\end{tabular}

women with and without diabetes, as the comparison was with age-adjusted prevalence rates from the EUROCAT network of population-based registries [2]. The current study estimated a 3.8-fold increase, based on a direct comparison of the congenital anomaly rates in women with and without diabetes from the same source population, indentified independently of diabetes status.

Only two variables, higher peri-conception $\mathrm{HbA}_{1 \mathrm{c}}$ and pre-existing nephropathy, were significant independent predictors in multivariate analysis. Parity and gestational age at booking were retained in the multivariate model but the associations did not reach statistical significance. There was no evidence of an independent effect of maternal age, smoking, ethnicity and early pregnancy BMI, which have been associated with congenital anomaly risk in the general population. A higher rate of congenital anomaly was observed in women resident in more deprived areas; this was largely attributable to higher peri-conception $\mathrm{HbA}_{1 \mathrm{c}}$ in these women. We found no evidence that the increased risk of anomaly in women with diabetes was specific to males, in contrast with an earlier report [23], although we confirmed the increased risk for males in the general population [24, 25]. There was no evidence that any of the identified predictors of congenital anomaly were different in type 1 and type 2 diabetes.

Peri-conception $\mathrm{HbA}_{1 \mathrm{c}}$ was the most important independent predictor of congenital anomaly risk, confirming previous reports [4-6]. The current study identified a linear relationship with $\mathrm{HbA}_{1 \mathrm{c}}$ for values between $6.3 \%$ and $11 \%$ (45 and $97 \mathrm{mmol} / \mathrm{mol}$ ). The odds were lowest for $\mathrm{HbA}_{1 \mathrm{c}}=$ $6.3 \%$ (45 $\mathrm{mmol} / \mathrm{mol})$, although still above background population levels, and increased by approximately $2 \%$ in absolute terms for each $1 \%(11 \mathrm{mmol} / \mathrm{mol})$ increase, slightly lower than previous reports $[5,6]$. We found no evidence of further reduction for values below $6.3 \%$ (45 $\mathrm{mmol} / \mathrm{mol})$, although there were few individuals in this range.

Current guidance from the American Diabetes Association recommends a target $\mathrm{HbA}_{1 \mathrm{c}}<7 \%$ (53 $\left.\mathrm{mmol} / \mathrm{mol}\right)$ prior to pregnancy [26]. In England, the National Institute for Health and Clinical Excellence (NICE) suggests a target for preconception $\mathrm{HbA}_{1 \mathrm{c}}<6.1 \%$ (43 $\left.\mathrm{mmol} / \mathrm{mol}\right)$, if safely achievable, and strongly discourages pregnancy at levels $>10 \%$ (86 $\mathrm{mmol} / \mathrm{mol}$ ) [27]. Our results indicate that there appears to be no specific threshold for change in congenital anomaly risk, and hence do not provide support for particular periconception $\mathrm{HbA}_{1 \mathrm{c}}$ targets, but rather provide risk estimates across a range of $\mathrm{HbA}_{1 \mathrm{c}}$ levels. Our results further suggest that even achieving near normal levels of $\mathrm{HbA}_{1 \mathrm{c}}$ does not eliminate the increased risk of congenital anomaly attributable to diabetes. All women with diabetes should be encouraged to achieve as great a reduction in $\mathrm{HbA}_{1 \mathrm{c}}$ as possible prior to conception.

There was a greater than twofold increased risk of congenital anomaly in the offspring of women with pre-existing nephropathy. This group is known to be at increased risk of adverse pregnancy outcome [28, 29], but this is the first 
study to suggest a specific increased risk of occurrence of congenital anomaly. This finding requires confirmation in other studies. Nephropathy may reflect a history of prolonged poor glycaemic control, including high variability in glucose levels, which may not be reflected by $\mathrm{HbA}_{1 \mathrm{c}}$ [30]; however, neither retinopathy nor neuropathy conferred increased risks of congenital anomaly. Women with nephropathy usually require antihypertensive medication and are often treated with ACE inhibitors, which have been associated with congenital anomaly risk [31]. Current guidance suggests that these and other potentially teratogenic medications should be discontinued prior to conception [27, 32] but many pregnancies are unplanned and the extent of peri-conception exposure to potentially teratogenic medications is unknown. We were unable to investigate this issue as the registers do not record details of peri-conception medications. There is evidence for a genetic influence on diabetic nephropathy, and it is possible that an association with congenital anomaly may have a genetic basis [33]. Oxidative stress is thought to play a role in the development of nephropathy as well as in congenital anomaly [34]. These potential shared mechanisms merit further research.

Type of diabetes was not independently associated with risk of congenital anomaly, and did not modify the association with other variables. There was a slightly higher unadjusted risk of non-chromosomal anomaly among women with type 1 diabetes (RR 1.4 [95\% CI 0.9, 2.2]), which may have been significant with a larger sample size; however the effect was heavily attenuated by adjustment for $\mathrm{HbA}_{1 \mathrm{c}}$, suggesting that this is the main driver for any difference in risk between type 1 and type 2 . Women with type 2 diabetes had lower periconception $\mathrm{HbA}_{1 \mathrm{c}}$, but were less likely to attend for preconception care, and had markedly different clinical and sociodemographic characteristics compared with women with type 1 diabetes, in line with previous reports [35, 36]. Specific approaches to improve pregnancy planning in women with type 2 diabetes may be required. Reported rates of preconception folate supplementation were generally low, suggesting poor awareness among women and/or low rates of planned pregnancies.

This study confirms the association of pre-existing diabetes with a wide range of non-chromosomal anomalies affecting most major organ systems $[20,37]$ and with the risk of anomalies affecting multiple systems [37, 38] Cardiovascular anomalies were the most common, reflecting their high frequency in the general population, and were not proportionally more frequent in women with diabetes. However, we confirmed very high relative risks for caudal regression sequence and laterality syndrome [38, 39], suggesting a specific effect of diabetes in the aetiology of these rare anomalies.

Given the diverse range of congenital anomalies associated with maternal diabetes, mechanisms that have a general effect on early organogenesis are likely [40, 41]. Hyperglycaemia may be directly implicated through induction of oxidative stress within the embryo [42]. Disruption of specific genetic pathways in this way has been described in animal models for neural tube and cardiac outflow tract development [43].

Blood glucose levels may fluctuate widely, even in the presence of apparently 'optimal' $\mathrm{HbA}_{1 \mathrm{c}}$ [30]. Multiple anomalies may arise from multiple episodes of hyperglycaemia during the critical windows of development for different organ systems. Hence, approaches to reducing peri-conception glucose variability using insulin pump therapy and continuous glucose monitoring may be valuable in the prevention of congenital anomaly and should be evaluated in this regard [44].

Implications Women with diabetes remain at greatly increased risk of offspring affected by major congenital anomaly. Achieving optimal glycaemic control prior to conception remains the most important modifiable risk factor, but is unlikely to eliminate the excess risk. Guidelines emphasise the provision of specialist preconception care to improve preparation and planning for pregnancy, but uptake remains low, and women from ethnic minority groups, socially deprived areas and with type 2 diabetes are less likely to attend. Awareness of the need for preparation for pregnancy should be incorporated into the routine care of young women with diabetes. Further research is needed to evaluate new approaches to improve the number of women with diabetes who are adequately prepared for pregnancy, and to reduce sociodemographic inequalities in outcome.

We found that women with pre-existing nephropathy were at particularly high risk of congenital anomaly. These women require specific care and support to achieve a planned pregnancy with a good outcome. Further investigation of the extent and consequences of exposure to potentially teratogenic factors in these women, including medications, is required. Interventions to reduce glucose variability and anti-oxidant therapies merit further assessment of their potential to reduce congenital anomaly risk in women with diabetes.

Acknowledgements We are grateful to all the district convenors and coordinators in the north of England for their continued collaboration and support of NorCAS and NorDIP. We also thank the staff at the RMSO for their help in data tracing and checking. We are very grateful to C. Wright, Consultant Perinatal Pathologist, Royal Victoria Infirmary, Newcastle upon Tyne; P. Boyd, Clinical Director of the Congenital Anomaly Register for Oxford, Berkshire and Buckinghamshire (CAROBB), University of Oxford; and D. Wellesley, Head of Prenatal Genetics, Southampton University Hospitals Trust, for their expert advice on coding and classification of congenital anomalies.

Funding This study was funded by Diabetes UK (BDA number: 10/ 0004019). NorCAS is funded by the UK Department of Health/Healthcare Quality Improvement Partnership. NorDIP is funded by the four Primary Care Trusts in North East England. 
Duality of interest The authors declare that there is no duality of interest associated with this manuscript.

Contribution statement $\mathrm{RB}$ and JR developed the study concept and supervised the research. SVG prepared the database and PWGT coded the anomalies. SVG and PWGT analysed the data, and with RWB, RB and JR, interpreted the findings. RB wrote the first draft of the report; all co-authors contributed to writing and agreed the final draft.

\section{References}

1. Balsells M, Garcia-Patterson A, Gich I, Corcoy R (2009) Maternal and fetal outcome in women with type 2 versus type 1 diabetes mellitus: a systematic review and metaanalysis. J Clin Endocrinol Metab 94:4284-4291

2. Macintosh MC, Fleming KM, Bailey JA et al (2006) Perinatal mortality and congenital anomalies in babies of women with type 1 or type 2 diabetes in England, Wales, and Northern Ireland: population based study. BMJ 333:177-180

3. Persson M, Norman M, Hanson U (2009) Obstetric and perinatal outcomes in type 1 diabetic pregnancies: a large, population-based study. Diabetes Care 32:2005-2009

4. Inkster ME, Fahey TP, Donnan PT, Leese GP, Mires GJ, Murphy DJ (2006) Poor glycated haemoglobin control and adverse pregnancy outcomes in type 1 and type 2 diabetes mellitus: systematic review of observational studies. BMC Pregnancy Childbirth 6:30

5. Evers IM, de Valk HW, Visser GH (2004) Risk of complications of pregnancy in women with type 1 diabetes: nationwide prospective study in the Netherlands. BMJ 328:915

6. Suhonen L, Hiilesmaa V, Teramo K (2000) Glycaemic control during early pregnancy and fetal malformations in women with type I diabetes mellitus. Diabetologia 43:79-82

7. Bell R, Bailey K, Cresswell T, Hawthorne G, Critchley J, LewisBarned N (2008) Trends in prevalence and outcomes of pregnancy in women with pre-existing type I and type II diabetes. BJOG 115:445-452

8. Richmond S, Atkins J (2005) A population-based study of the prenatal diagnosis of congenital malformation over 16 years. BJOG 112:1349-1357

9. EUROCAT Coding of EUROCAT subgroups of congenital anomalies. Available from www.eurocat-network.eu/content/EUROCATGuide-1.3.pdf. Accessed 15 July 2010

10. EUROCAT EUROCAT syndrome guide: definition and coding of syndromes. Available from www.eurocat-network.eu/content/ EUROCAT-Syndrome-Guide-6-2008.pdf. Accessed 15 July 2010

11. Opitz J (1994) Association and syndrome: terminology in clinical genetics and birth defects epidemiology. Am J Med Genet 49:14 20

12. Spranger J, Benirschke K, Hall J et al (1982) Errors of morphogenesis: concepts and terms. J Pediatr 100:160-165

13. Long JS, Freese J (2000) sg152: Listing and interpreting transformed coefficients from certain regression models. Stata Technical Bulletin 57:27-34

14. Rankin J, Tennant PW, Stothard KJ, Bythell M, Summerbell CD, Bell R (2010) Maternal body mass index and congenital anomaly risk: a cohort study. Int J Obes 34:1371-1380

15. Noble M, McLennan D, Wilkinson K, Whitworth A, Barnes H, Dibben C (2008) The English indices of deprivation 2007. In: Department for Communities and Local Government (ed), London
16. Aberg A, Westbom L, Kallen B (2001) Congenital malformations among infants whose mothers had gestational diabetes or preexisting diabetes. Early Hum Dev 61:85-95

17. Eidem I, Stene LC, Henriksen T et al (2010) Congenital anomalies in newborns of women with type 1 diabetes: nationwide population-based study in Norway, 1999-2004. Acta Obstet Gynecol Scand 89:1403-1411

18. Jensen DM, Damm P, Moelsted-Pedersen L et al (2004) Outcomes in type 1 diabetic pregnancies: a nationwide, population-based study. Diabetes Care 27:2819-2823

19. Pearson DW, Kernaghan D, Lee R, Penney GC (2007) The relationship between pre-pregnancy care and early pregnancy loss, major congenital anomaly or perinatal death in type I diabetes mellitus. BJOG 114:104-107

20. Sharpe PB, Chan A, Haan EA, Hiller JE (2005) Maternal diabetes and congenital anomalies in South Australia 1986-2000: a population-based cohort study. Birth Defects Res A Clin Mol Teratol 73:605-611

21. Casson IF, Clarke CA, Howard CV et al (1997) Outcomes of pregnancy in insulin dependent diabetic women: results of a five year population cohort study. BMJ 315:275-278

22. Dunne F, Brydon P, Smith K, Gee H (2003) Pregnancy in women with type 2 diabetes: 12 years outcome data 1990-2002. Diabet Med 20:734-738

23. Evers IM, de Valk HW, Visser GH (2009) Male predominance of congenital malformations in infants of women with type 1 diabetes. Diabetes Care 32:1194-1195

24. Shaw GM, Carmichael SL, Kaidarova Z, Harris JA (2003) Differential risks to males and females for congenital malformations among 2.5 million California births, 1989-1997. Birth Defects Res A Clin Mol Teratol 67:953-958

25. Tennant PWG, Samaresekera SD, Pless-Mulloli T, Rankin J (2011) Sex differences in the prevalence of congenital anomalies: a population based study. Birth Defects Res A: Clin Mol Teratol 91:894-901

26. American Diabetes Association (2011) Executive Summary: Standards of Medical Care in Diabetes-2011. Diabetes Care 34:S4-S10

27. National Institute for Health and Clinical Excellence (2008) Diabetes in pregnancy: management of diabetes and its complications from pre-conception to the postnatal period. NICE Clinical Guideline 63. Available from www.nice.org.uk/nicemedia/pdf/ CG063Guidance.pdf. Accessed 4 July 2011

28. Carr DB, Koontz GL, Gardella C et al (2006) Diabetic nephropathy in pregnancy: suboptimal hypertensive control associated with preterm delivery. Am J Hypertens 19:513-519

29. Dunne FP, Chowdhury TA, Hartland A et al (1999) Pregnancy outcome in women with insulin-dependent diabetes mellitus complicated by nephropathy. QJM 92:451-454

30. Kerssen A, Evers IM, de Valk HW, Visser GHA (2003) Poor glucose control in women with type 1 diabetes mellitus and 'safe' hemoglobin A1c values in the first trimester of pregnancy. $J$ Matern Fetal Neonatal Med 13:309-313

31. Cooper WO, Hernandez-Diaz S, Arbogast PG et al (2006) Major congenital malformations after first-trimester exposure to ACE inhibitors. N Engl J Med 354:2443-2451

32. Kitzmiller JL, Block JM, Brown FM et al (2008) Managing preexisting diabetes for pregnancy. Diabetes Care 31:1060 1079

33. Doria A (2010) Genetics of diabetes complications. Current Diabetes Reports 10:467-475

34. Forbes JM, Coughlan MT, Cooper ME (2008) Oxidative stress as a major culprit in kidney disease in diabetes. Diabetes 57:14461454

35. Murphy HR, Roland JM, Skinner TC et al (2010) Effectiveness of a regional prepregnancy care program in women with type 1 and type 2 diabetes. Diabetes Care 33:2514-2520 
36. Tripathi A, Rankin J, Aarvold J, Chandler C, Bell R (2010) Preconception counseling in women with diabetes: a populationbased study in the north of England. Diabetes Care 33:586588

37. Nielsen GL, Norgard B, Puho E, Rothman KJ, Sorensen HT, Czeizel AE (2005) Risk of specific congenital abnormalities in offspring of women with diabetes. Diabet Med 22:693-696

38. Martinez-Frias ML (1994) Epidemiological analysis of outcomes of pregnancy in diabetic mothers: identification of the most characteristic and most frequent congenital anomalies. Am J Med Genet 51:108-113

39. Splitt M, Wright C, Sen D, Goodship J (1999) Left-isomerism sequence and maternal type-1 diabetes. Lancet 354:305-306
40. Zabihi S, Loeken MR (2010) Understanding diabetic teratogenesis: where are we now and where are we going? Birth Defects Res A Clin Mol Teratol 88:779-790

41. Eriksson UJ (2009) Congenital anomalies in diabetic pregnancy. Semin Fetal Neonatal Med 14:85-93

42. Ornoy A (2007) Embryonic oxidative stress as a mechanism of teratogenesis with special emphasis on diabetic embryopathy. Reprod Toxicol 24:31-41

43. Wentzel P (2009) Can we prevent diabetic birth defects with micronutrients? Diabetes Obes Metab 11:770-778

44. Murphy HR, Rayman G, Lewis K et al (2008) Effectiveness of continuous glucose monitoring in pregnant women with diabetes: randomised clinical trial. BMJ 337:a1680 